NOTE

\title{
Disseminated Mycobacterium intracellulare infection in a broad-snouted caiman Caiman latirostris
}

\author{
Marja J. L. Kik* \\ ${ }^{1}$ Utrecht University, Faculty of Veterinary Medicine, Pathobiology, Yalelaan 1, 3584 CL, Utrecht, The Netherlands \\ ${ }^{2}$ Veterinarian specialist for reptiles and amphibians, Melissegaarde 16, $3436 \mathrm{HZ}$, Nieuwegein, The Netherlands
}

\begin{abstract}
A 10 yr old broad-snouted caiman Caiman latirostris from a small Dutch animal park was presented with long-term variable periods of anorexia and weight loss. Blood chemistry showed slightly elevated uric acid levels and low ionised calcium concentration. Ultrasonographical thickening of the intestinal wall in the region of the duodenum was evident. Pathological changes were a thickening of the wall of $90 \%$ of the small intestines, enlarged spleen with multifocal white foci and an enlarged light-brown liver. Histopathological lesions consisted of disseminated granulomas in the intestinal wall, the liver and the spleen. Multinucleated giant cells and epitheloid macrophages were abundant. Ziehl-Neelsen staining showed numerous intralesional acid-fast bacteria. Polymerase chain reaction for Mycobacterium intracellulare was positive.
\end{abstract}

KEY WORDS: Mycobacteriosis · Caiman · Mycobacterium intracellulare · Caiman latirostris · Broad-snouted caiman

Resale or republication not permitted without written consent of the publisher

\section{INTRODUCTION}

Non-tuberculous mycobacteria (NTM) are found in the environment and are opportunistic pathogens. Mycobacterium intracellulare is an NTM that can cause disease in immunosuppressed but also in nonimmunosuppressed humans and non-domestic mammals, non-human primates and exotic hoofstock. In non-immunosuppressed persons, the manifestation of NTM infection can be severe pulmonary disease. Recent studies indicate that NTM pulmonary disease in the USA occurs more frequently than tuberculosis (Winthrop et al. 2010). In Queensland, Australia, it is a notifiable condition (Thomson 2010). An increase in the number of referred NTM has also been noted in the Netherlands (van Ingen et al. 2010). M. intracellulare is readily aerosolized from aqueous suspension and enters the alveoli of the lung and is thus a threat to people working in a water-rich environment. $M$. intracellulare has been recovered from drinking water, household plumbing and hospitals (Falkinham 2003). NTM are thought to have emerged as pathogens with important environmental and public health implications (Winthrop et al. 2011). In many aquariums, animal caretakers clean the facility with a high-pressure water hose, thus creating aerosols: in the case reported here, a sprinkler system was used 4 times a day to increase the relative humidity in the enclosure. In such instances, then, the presence of $M$. intracellulare-shedding reptiles presents a threat to human health. However, to date there have been no studies on the shedding of mycobacteria in a captive environment. Indeed, there has been very little research on NMT in crocodilian species at all (Ariel et al. 1997). According to Huchzermeyer (1997), mycobacteriosis is extremely rare in crocodiles and is therefore no threat to humans consuming the meat of farmed or wild crocodilians. M. szulgai has been reported in freshwater crocodiles Crocodylus johnstoni in captivity (Roh et 
al. 2010). Different NMT have been described in many other species of reptiles, but these were mostly M. marinum, $M$. chelonae, $M$. fortuitum, $M$. smegmatis or $M$ phlei, $M$. marinum being by far the most reported NTM in reptiles (Huchzermeyer 1997).

The present report describes a case of disseminated Mycobacterium intracellulare in a broadsnouted caiman Caiman latirostris in a small Dutch animal park.

\section{METHODS AND RESULTS}

The animal was housed with another adult female caiman of approximately the same age in a large exhibit with both a dry land and a water component. The environmental temperature was between 26 and $28^{\circ} \mathrm{C}$. The animals were fed a diet consisting of fish and adult rats. Both animals were imported to Europe from Argentina as juvenile farm-bred animals; they moved to this park $4 \mathrm{yr}$ later. The $10 \mathrm{yr}$ old male broad-snouted caiman had a chronic history ( $>1 \mathrm{yr}$ ) of variable periods of anorexia and weight loss. On clinical examination, the animal was emaciated: he was $1.7 \mathrm{~m}$ long and weighed $11 \mathrm{~kg}$; the mucosal membranes of the mouth were white. The haematocrit value was $10 \%$ (22 to $25 \%$ ). The animal resisted deep palpation in the area just caudal to the last rib. Blood chemistry revealed a slightly elevated uric acid level, $4.7 \mathrm{mg} \mathrm{dl}^{-1}$ plasma (3.2 to $4.3 \mathrm{mg} \mathrm{dl}^{-1}$ ), and low ionized calcium concentration of $1.21 \mathrm{mmol} \mathrm{l}^{-1}$ plasma (1.47 $\mathrm{mmol} \mathrm{l}^{-1}$ plasma). Ultrasonographical examination showed a thickened wall of part of the small intestine $(1.5 \mathrm{~cm})$; the lumen was practically obliterated. Based on all examinations and the very poor condition of the animal, the owners decided not to surgically explore the intestine but to have the animal euthanized.

On gross pathology, based on muscle development and lack of fat storage, the animal was cachectic, there was clear fluid in the coelomic cavity $\left(\begin{array}{ll}1 & 1\end{array}\right)$, $>90 \%$ of the small intestine had a thickened wall (Fig. 1), the content was hemorrhagic, the spleen was enlarged with multifocal white foci, and the liver was enlarged and pale brown. The lungs were oedematous. The pericardium contained clear fluid $(10 \mathrm{ml})$. Tissue samples from the small intestine, spleen, lung, liver and kidneys were fixed in $4 \%$ phosphatebuffered formalin, embedded in paraffin, cut into $4 \mu \mathrm{m}$ sections and stained with hematoxylin and eosin (H\&E) and Ziehl-Neelsen staining. Duplicate samples of each of these tissues were stored at $-80^{\circ} \mathrm{C}$ for further evaluation.

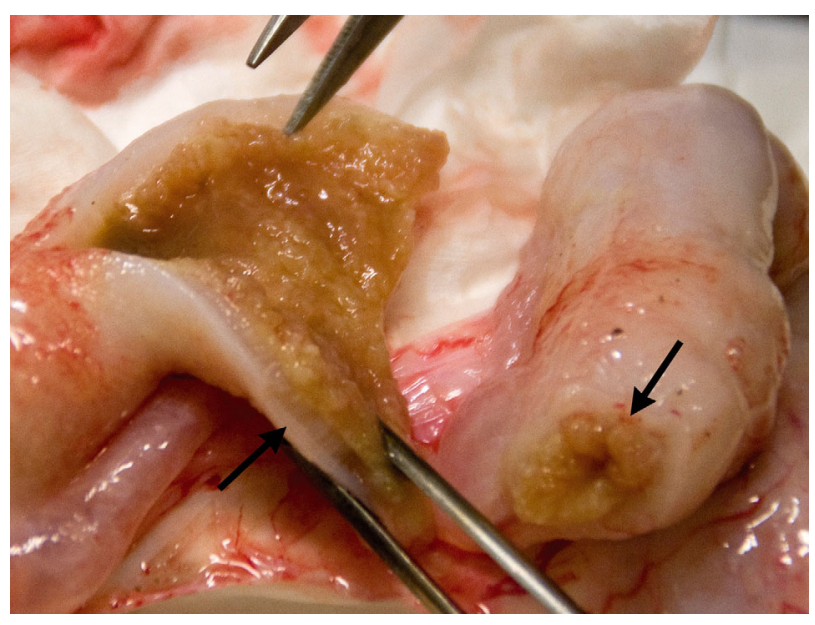

Fig. 1. Caiman latirostris. The jejunum of the caiman. The intestinal wall is thickened; the lumen is practically obliterated (arrows)

Histopathologic lesions consisted of disseminated granulomas throughout the intestinal wall, liver and spleen. The centres of the granulomas were composed of necrosis surrounded by multinucleated giant cells and epitheloid macrophages. (Fig. 2) Ziehl-Neelsen staining showed numerous intralesional acid-fast bacteria (Fig. 3). The lungs showed interstitial lymphocytic infiltrations. Urate stasis was present in the renal tubules.

Tissue samples were decontaminated according to the method described by Beerwerth (1967) and cultivated on modified Lowenstein-Jensen medium supplemented with $4 \mathrm{mg} \mathrm{ml}^{-1}$ pyruvate (Jørgensen 1982). The first colonies were isolated after $3 \mathrm{wk}$ of incubation.

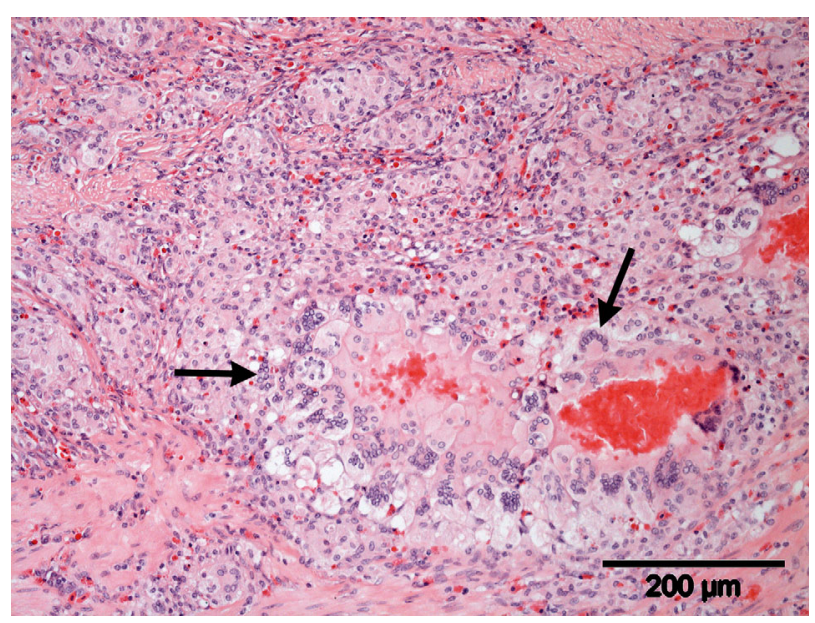

Fig. 2. Jejunum of the caiman with typical central necrosis surrounded by multinucleated giant cells (arrows) and epitheloid macrophages. H\&E staining. Scale bar $=200 \mu \mathrm{m}$ 


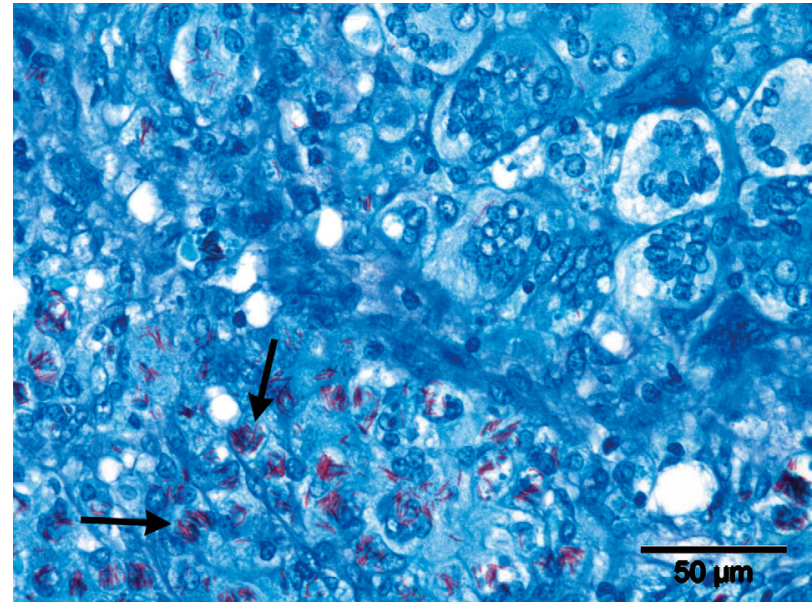

Fig. 3. Ziehl-Neelsen staining of the jejunum. Note the intralesional acid-fast rod-shaped bacteria (arrows). Scale bar $=$ $50 \mu \mathrm{m}$

Individual colonies were taken and transferred to fresh slants for further culture. Incubation was continued for a total of $6 \mathrm{wk}$.

For identification of the cultures, a PCR in combination with a reverse cross blot hybridization assay (Kox et al. 1995) and a 16S sequence analysis were performed. DNA was extracted by boiling for $10 \mathrm{~min}$.

Part of the DNA-encoding 16S rRNA was amplified using primers p90AFBio (5'-TTC TTG AAG GGT GTT CGG GGC CGT CG-3') and p90rev (5'-TCT TTG GCG TCG GTC TTG CCT TCG CC-3'). Analysis of the PCR product was performed using the $\mathrm{Myco}$ bacterium intracellulare specific probe, pInt7R 169147 (5'-CAC CAA AAG ACA TGC GTC TAA-3'). PCR products obtained with all isolates reacted with this probe, thereby identifying these isolates as $M$. intracellulare. Also, a 500 bp $16 \mathrm{~S}$ rDNA fragment was amplified and subsequently sequenced using the MicroSEQ ${ }^{\circledR} 50016$ S rDNA Bacterial Identification System (Applied Biosystems) and an ABI 3130 Genetic Analyzer (Applied Biosystems) according to the manufacturer's instructions. The obtained sequences were compared with the NCBI database (www.ncbi.nlm.nih.gov) using BLASTN. On the basis of this comparison, the isolates were identified as $M$. intracellulare.

\section{DISCUSSION}

This animal may have been immunocompromised because of environmental temperatures that were too low during winter a year before the onset of clinical signs. It is possible that the animal was shedding the bacteria into its environment and that staff working there were exposed to the organisms via water contact through aerosolization and inhalation and, to a lesser extent, ingestion while in the water. Hygienic measures for the staff, as advised by the Central Veterinary Institute, Lelystad, the Netherlands, consisted of showering after diving. Based on the risk of aerosolization of water contaminated with Mycobacterium intracellulare, higher standards of staff protection are warranted. As reported, in the USA, pulmonary NMT disease probably outnumbers cases with $M$. tuberculosis (Winthrop et al. 2010). NTM, and more specifically $M$. intracellulare, thrive in humid, warm enclosures, such as the one in which this caiman was housed. As considered appropriate in immersion, naturalistic exhibits in zoos and animal parks, visitors walk through the enclosure of the animals and may be exposed to aerosolized $M$. intracellulare (Falkinham 2011). Therefore, measures should be taken to minimize the risk of exposure to this and other types of mycobacteria for the staff and for visiting persons. For example, the enclosure should be cleaned with water with a temperature higher than $60^{\circ} \mathrm{C}$. Sprinkler systems that may create aerosols and high-pressure water hoses should not be used (Falkinham 2003, Thomson 2010). So far, the female caiman and the fish in the aquarium seem healthy.

Acknowledgements. The author thanks Dr. R. Fleish for proofreading, J. Fama for editing of the photographs and F. Vugts for assistance with the animal, Dr. F. van Asten for correcting part of the text and Dr. D. Bakker from the Central Veterinary Institute Lelystad, 8221 RA Lelystad, The Netherlands, for culturing and identifying the mycobacteria.

\section{LITERATURE CITED}

Ariel E, Ladds PW, Roberts BL (1997) Mycobacteriosis in young freshwater crocodiles (Crocodylus johnstoni). Aust Vet J 75:831-833

Beerwerth W (1967) The culture of mycobacteria from the faeces of domestic animals and their significance for the epidemiology of tuberculosis. Prax Pneumol 21: 189-202

Falkinham JO III (2003) Mycobacterial aerosols and respiratory disease. Emerg Infect Dis 9:763-767

> Falkinham JO III (2011) Nontuberculous mycobacteria from household plumbing of patients with nontuberculous mycobacteria diseases. Emerg Infect Dis 17:419-424

> Huchzermeyer FW (1997) Public health risks of ostrich and crocodile meat. Rev Sci Tech 16:599-604

Jørgensen JB (1982) An improved medium for culture of Mycobacterium paratuberculosis from bovine feces. Acta Vet Scand 23:325-335

> Kox LFF, Van Leeuwen J, Kuijper S, Jansen HM, Kolk AHJ (1995) PCR assay based on DNA coding for 16S rRNA for 
detection and identification of mycobacteria in clinical samples. J Clin Microbiol 33:3225-3233

Roh YS, Park H, Cho A, Rafiqul Islam M and others (2010) Granulomatous pneumonia in a captive freshwater crocodile (Crocodylus johnstoni) caused by Mycobacterium szulgai. J Zoo Wildl Med 41:550-554

Thomson RM (2010) Changing epidemiology of pulmonary nontuberculous mycobacteria infections. Emerg Infect Dis 16:1576-1583

van Ingen J, Hoefsloot W, Dekhuijzen PNR, Boeree MJ, van Soolingen D (2010) The changing pattern of clinical

Editorial responsibility: Alex Hyatt,

Geelong, Victoria, Australia
Mycobacterium avium isolation in the Netherlands. Int J Tuberc Lung Dis 14:1176-1180

Winthrop KL, McNelley E, Kendall B, Marshall-Olson A and others (2010) Pulmonary nontuberculous mycobacterial disease prevalence and clinical features: an emerging public health disease. Am J Respir Crit Care Med 182: 977-982

Winthrop KL, Varley CD, Ory J, Cassidy PM, Hedberg K (2011) Pulmonary disease associated with nontuberculous mycobacteria, Oregon, USA. Emerg Infect Dis 17: 1759-1761

Submitted: January 2, 2013; Accepted: July 30, 2013

Proofs received from author(s): November 7, 2013 